\title{
Diet and Cancer.
}

THERE have been and are all sorts of statements 1 about the relation of diet to the occurrence of cancer. We are told that eating raw carrots will prevent and even cure it; others attribute efficacy to onions, others to a salt-free diet ; tomatoes, on the other hand, have been suspected of causing cancer. Particularly common is the suggestion, which appears at times to have crystallised into a belief, that vegetarians suffer from malignant disease less than ordinary people who take a fleshy diet.

None of these statements has been subjected to critical inquiry; and indeed such inquiry is by no means easy, for it is hard to find two bodies of persons, in other respects wholly comparable, who differ only in their enjoyment or rejection of meat. The vegetarians in Great Britain, for example, could not, without the strictest inquiry, be regarded as a sample of the population which differed from the normal only in their avoidance of meat; there are many grades and subclasses of vegetarians, but, taken as a whole, they form a group distinguished in many modes of life and thought besides their diet. In the world at large, vegetarianism, in short, is generally a character associated with other exceptional features of body and mind, and any advantage or disadvantage which vegetarians may show in the incidence of disease may be due to their general make-up as likely as to the nominal outward sign of it. The study of such associations in man is, indeed, difficult, and is liable to be extremely fallacious.

Particularly welcome, therefore, is the report on the incidence of cancer in certain religious orders by Dr. S. Monckton Copeman and Dr. Major Greenwood. With the co-operation of the ecclesiastical authorities and with an amount of detailed inquiry which must have been even more troublesome than it seems, they have collected the necessary statistics in a number of religious houses in England and elsewhere. 'The

1 Ministry of Health. Reports on Public Health and Medical Subjects, No. 36: Diet and Cancer, with Special Reference to the Incidence of Cancer upon Members of certain Religious Orders. By Dr. S. Monckton Copeman and Major Greenwcod. Pp. iv +33 . (London: H.M. Staticnery Office, 1.926.) $9 d$. net. monks, nuns, and lay brothers in these communities are all essentially vegetarians : but we can be pretty sure that vegetarianism is no more than an incidental circumstance, and that the nature of the diet has had no influence in determining the membership of these communities. Among the Carthusians and Cistercians the rules are especially strict, and a life which is spent in silence in a cell from which the monk comes out only for a nightly service, for a meal in the refectory on Sundays, and for a weekly walk, cannot be said to involve much of that hurry, luxury, and excess to which cancer and other sickness is so often ascribed. But the results of this minute inquiry into their mortality shows that, while perhaps as a whole the mortality is in some instances rather less than would be expected in persons of similar age and sex in the outside world, there is no evidence at all of any immunity to cancer. Thus in a Cistercian house in England, 427 people lived between 1800 and 1920 : there were 104 deaths against an expectation of 82 in the general population, and of these 5 certainly, and 3 probably, died of cancer, as compared with 5 or 6 in non-monks. Cistercian nuns in England and a Belgian house of the same order give similar results, as do Benedictine and Carmelite communities in which the rules are not quite so strict. Taken separately or together, the figures lend no support to a proposition that cancer is either less or more common inside monasteries than among the contemporary comparable part of the population outside.

Finally, data are given which were. collected less minutely and completely from 57 Cistercian houses in different parts of the world : the figures seem to show a singularly small number of deaths from cancer, but, as the authors point out, the calculations are subject in these instances to so many qualifications that one is once again reduced to the conclusion that there is no evidence of any difference either way. Any one who feels inclined to rush in and solve the problem of the causation of cancer by statistical methods should study carefully this admirable example of how such work should be done : it is much more difficult than some enthusiasts imagine.

\section{Maori Navigation.}

THE vessels used by the peoples of the Pacific in their migrations and colonisations are of primary importance in Oceanic ethnology. They have been described by various writers, but only partially, and generally from the technological side. Now, in an interesting Bulletin of the Dominion Museum of New Zealand, ${ }^{1}$ Mr. Elsdon Best has collected all that is known or can be learned from native sources about Maori canoes. Every aspect of the subject is discussed and fully illustrated by copies of early prints or modern photographs.

Some types of Maori canoes have entirely disappeared. The double canoe, formed by two dugouts united by a platform, survived until about 1830 . The occurrence of the single canoe with one outrigger is denied by some writers, although it is said to have been seen by Captain Cook. The single canoe with double outrigger is said to be only mentioned in tradition. This becomes important when it is noted that Indo-Javan vessels twelve centuries ago had double outriggers.

The only native canoe now used is that without an

1 New Zealand, Dominion Museum. Bulletin No. 7: The Maor Canoe. Ry Ilsdon Best. Published under the direction of the Board Ganoe. By Elsdon Best. Published under the direction of the Board N.Z. : W. A. G. Skinner, 1925.)

No. 2990, Vor. 119] outrigger. The generic name is waka. Varieties are distinguished as the waka taua, war canoe, waka tete used for fishing and travelling, and the waka titai and other small craft used in calm waters.

The building of the waka taua is fully described. The tree, of totara, kauri, or other timber, was reserved by clearing the bush around or by a taboo. A strip of bark might be peeled off one side to initiate decay and facilitate hollowing out. On an auspicious day, after fasting and ritual, the trunk was felled. Sometimes the lower part was scarfed, or the uncovered roots were burned, or an ingenious machine on the ballista principle was used. The trunk was charmed to prevent damage in falling. The hollowing was performed by burning and by the stone adze. Canoe makers wore only one garment, and their food, reserved for them alone, was cooked apart. It was etiquette for a visitor to throw his spear at the canoe. If it stuck, the omen was favourable. The hull was hauled to the water side by ropes, often for long distances, by many people. Charmed skids eased the canoe over rough ground. Sometimes the hull was composed of more than one piece.

The sides of the dug-out were heightened by an ornamental top strake, butted and lashed to its top edge by strings of flax, and caulked with fibre. The 
join was covered by a batten. The ends of the top strake were drawn in by a tourniquet and the lashings tightened with a lever. The ends of the dug-out were fitted with figure-head and stern piece, coloured red and black and ornamented with feathers. The deck was a mere grating. The launch was carried out according to ritual and was followed by a ceremonial feast.

Mr. Best describes in less detail the fishing and river canoes, and also the canoes of the Chatham Islands. An account is also given of ceremonial observances in the use of canoes.

The common mode of propulsion was the paddle, but poling was often resorted to when ascending streams or in shallow water. Steering was effected by a long paddle at the stern or by directions to the paddlers. Mr. Best gives specimens of the songs sung while paddling. The sails formerly used were triangular, with the small end downward. They were made of matting or laced leaves. Generally only one sail was used, but large canoes might have two or three. Stones were used as anchors. They were used in the natural state or with grooves pecked round the middle to fit the rope, or in baskets. Baling was performed with carved balers having the handles projecting forward.

Mr. Best gives a summary account of canoes of the Pacific area, quoting from various authors. Gilbert and Loyalty Island canoes are included with the Polynesian, and only short notes are given on those of Melanesia, Micronesia, and Indonesia. At the end of this chapter Maori methods of navigation are described, and the Maori and Moriori compass points enumerated, without reference to other island names.
An interesting chapter is devoted to Maori traditions of the discovery and settlement of New Zealand by visitors from eastern Polynesia, from an island Hawaiki, which Mr. Best identifies with Tahiti. The first voyagers were Kupe and Ngahue. They circumnavigated New Zealand and named it Aotea-roa. They found no human inhabitants but reported on their return to Hawaiki that the most valuable products of Aotea-roa were the moa and pounamu (nephrite). Toi, a later visitor, found the islands inhabited by the Maruiwi or Mouriuri, a dark-skinned people with bushy hair. The voyage of Toi and that of his grandson Whatonga led to the colonisation of New Zealand, and voyages thereto became frequent. Mr. Best gives an account of Maori. voyages and the historic canoes in which they were made.

With its list of Maori navigation terms, bibliography, and index, the work forms a valuable compendium and record of one group of Polynesian canoe builders and navigators, and Mr. Best has done real service to Oceanic ethnology by its compilation.

In some places the linguistic comparisons are weak. Tonga hama, Rotuma sama, Fiji thama are assumed to be derivatives of the Maori ama (outrigger). The Tonga fohe and Samoa foe are said to come from the Maori word hoe (paddle). The Fijian wanka (canoe and shrine) is said to be a Maori term. But the names as found in Tonga, Rotuma, and Fiji are older than in Maori. The original words were semang or soman (outrigger), as in the Moluccas and Batjan; boseh, borsi, or bogsai (paddle), as in Java, Sumatra, and the Philippines; and banka or wanga (canoe), as in the Philippines and Celebes.

\section{Planets and Periodicities.}

T.HE nineteenth century discarded horoscopy of 1 the weather with the other appurtenances of astrology. Dr. Z. Kamerling ${ }^{1}$ would have us reverse the verdict and employ the motions of the planets as the basis of long-range forecasting. His thesis is that widespread periodicities must have a cosmic origin, and sunspots having failed, there remain only the planets. Accordingly he investigates periodicities of the length of the 'synodic rotations,' that is, the intervals between the dates at which the various planets are nearest to the earth. (It appears that the theoretical basis of this planetary connexion has been given in a previous paper; one wonders what it can possibly be.) These give him in years: Venus $1 \cdot 60$, Mars $2 \cdot 13$, Jupiter $1 \cdot 09$, Saturn 1.035, Uranus 1.018. As material he has forty years of average monthly rainfall over east Java and over west Java, twenty years' rainfall at Pernambuco, and temperatures at Winnipeg, Königsberg, and Zwanenburg. The method is to write down the monthly data in sets corresponding with the 'synodic year,' so that, for example, all the months of perigee come in the same vertical column, and to plot the smoothed means of these columns. From his graphs Dr. Kamerling concludes that there are real periodicities corresponding with the synodic periods of each planet, giving maxima generally near perigee and secondary maxima near apogee.

Such a result would be of considerable importance if substantiated, as explaining the origin of a number of periodicities of a little more than a year which have been suggested from time to time, but unfortunately the author has not done all he might to prove his case. He does not express his periodicities as Fourier series, nor does he attempt to determine their exact length. The original data are given only for the east

I "Grondslagen voor een Weervoorspelling op langen Termijn." Door Dr. Z. Kamerling. 1: Enkelvoudige Periodon van Wijziging der
Weersgesteldheid. Pp. 30. (Leiden: A. W. Sijthoff, n.d.) n.p. No. 2990, VoL. 119]
Java rainfall, and here inspection shows that the annual variation has not been completely eliminated. They show, in fact, a residual mean annual variation with a range of $16 \mathrm{~mm}$., which is of the same order as the ranges of the planetary periods. The normal used apparently covers the first thirty-three years, so that the error is entirely concentrated in the last seven years, and falsifies any apparent periods up to 1.1 year. The supposed period for Uranus (1 year 4 days), with a range of $18 \mathrm{~mm}$., is almost entirely due to this residual annual variation. The author does not give the standard deviations of the data which he uses, so that no test of reality can be made. The Venus period in east Java, which has by far the largest range of any, may be taken as a test case. The amplitude of the corresponding Fourier series is found to be $9 \mathrm{~mm}$., and the standard deviation of the original 480 values is $63 \mathrm{~mm}$. The amplitude is therefore 4.5 times the expectancy on a chance basis, and the period seems to be real. Its exact length, however, turns out to be 1.58 year, while the "synodic year' of Venus is 1.60 year; this means that the maximum phase shifts by about $120^{\circ}$ in forty calendar years, which seems too great, and the interpretation suggested is that there is a periodicity in the east Java rainfall which happens nearly, but not quite, to coincide with the Venus synodic year.

The curve for Mars shows very little trace of the whole period, but a well-marked half-period of 1.06 year, which may be due to the residual annual variation in the data. The present writer is not impressed by the supposed approximation of the maxima to perigee and apogee, since to him the graphs rather suggest a haphazard distribution of phase. Hence it seems necessary for the author to repeat his work, using more refined methods of analysis, and where possible longer series of data. The title of the paper is a misnomer, since the results would be of little use for forecasting purposes.

C. E. P, B. 